\title{
Metropolitan Management and Spaces
}

\author{
Román Rodríguez González*
}

\begin{abstract}
Department of Geography. Faculty of Geography and History. Pza. Universidade 1., University of Santiago de Compostela, Spain
\end{abstract}

\begin{abstract}
The physical and functional growth of Spanish cities has been very intense over the past decades. This has brought about the appearance of the metropolitarisation phenomenon in a large number of cities, which, nevertheless, has not been paralleled with the formation of organizations able to manage this new spatial reality. This has produced a large number of malfunctions and problems in the administration of public services. In this analysis, the main problems that are derived from the maladjustment between the metropolitan space, as a geographical unit, and the territorial management formulas will be presented. And, secondly, an assessment of Spanish experience in the area of metropolitan management will be carried out.
\end{abstract}

Keywords: Municipal restructuring, metropolitan area, urban development, territorial cooperation, urban planning.

The city as a physical and functional organization has acquired new forms of growth over the past few decades. The traditional ways of defining a city have given way to new realities, which change very quickly, and make them become very complex spaces. Nevertheless, politicaladministrative structures evolve at a much slower pace, making management and planning notably more difficult, and introducing certain contradictions between the process of physical expansion and the systems of government. Even though terms such as governing, cooperation or management innovation are becoming more and more frequent in the speeches of politicians and technicians, the reality of the case of Spain and in other countries that surround Spain is that the basic administrative division, and the municipality artificially fragments the city as a physical and functional unit. Attempts to define the main urban-metropolitan agglomerations and many other cities, independent of their sizes, are based on an inadequate local policy framework.

The new urban culture advances towards the substitution of the compact city models by new forms of a dispersed city, starting with the spread of one unit family residential models and a more extensive use of space [1]. The dispersion of work centres (both tertiary and industrial) throughout the suburbs must also be recognized. Linked to this process of change are new issues, which urban managers must solve include: people mobility, consumption of land, and transport management.

Thus, we are witnessing the substitution of the idea of the city as a delimited unit, defined by precise limits, by concepts such as metropolitan area, and urban functional region", which define interaction spaces between a territory integrated by a reference urban center and other population nucleus placed in its surrounding zone of influence. Another frequently used concept is that of city region [2] where the city and its hinterland are seen as a social and functional unit.

*Address correspondence to this author at the Department of Geography. Faculty of Geography and History. Pza. Universidade 1., University of Santiago de Compostela, Spain; Tel: 34616424950; Fax: 0034986782042;

E-mail: roman.rodriguez@usc.es
The different interpretations about the city being provided by the social sciences tend to present it as a complex geographical unit, fragmented, and increasingly more discontinuous in its physical organization. Mobility flows acquire increasing importance and the space-functional interrelations increase in scale. At the same time there is agreement that its management is becoming more complicated due to the fact that the traditional power structures hinder both the city planning, and the management of collective services fundamental for the citizens' quality of life. Both are circumstances, which introduce governing difficulties in a growing number of urban/metropolitan spaces.

Additionally, there is a series of factors with a mainly socio-territorial basis, which are forming a new relationship framework, which supercedes the existing local administrative divisions. Thus, together with the increasing strong mobility of citizens and the increase of travel, with a growing differentiation among places of residence, leisure or work, many municipalities manage local services, which are regularly consumed or used by the population of other municipalities. Other examples are the location in certain units of facilities or services, which cover the necessities of a supra-municipal area, or the necessity of sharing the consumption of space to locate facilities, residential areas, or large communication infrastructures.

Faced with this situation, new approaches to provide solutions to deal with physical planning and methods of city management have become common. Thus, advances have been introduced regarding the planning theory starting from the strategic planning, with the elaboration of new polycentric director schemes for urban areas, with the promotion of the cooperation between the different actors interacting in an area, etc. Essentially, this new approach seeks to overcome the rigidity and excessive regulations of traditional planning methods, which, definitively, means recognizing the necessity to modify the relationships between territorial and political structures that are outdated. 


\section{METROPOLITAN SPACES MANAGEMENT PROBLEMS}

Spain, in spite of its late urbanization, is becoming more and more urban. In recent decades, the cities and their bordering municipalities have grown demographically and functionally, with construction proceeding at unprecedented rates, as can be seen in the attached Table 1 . The intense urbanizing process implies building new houses, infrastructures, large facilities or services (airports, universities, shopping malls, sport facilities, etc.), and circumstances that make the original urban spaces physically grow beyond their own administrative limits. This expansion process causes the appearance of new urban areas, in which buildings and functional links exceed the original limits. The necessity to occupy space linked to the city growth gives way to the appearance of an urban continuum of growing expansion, and to a strong mobility of its citizens (as it is manifested by S. Perritaz [3]). The result of this process, already identified in a large number of Spanish urban spaces nowadays, but which, no doubt, will be accentuated in the future, is the lack of correlation between the administrative structures and the social, economic, cultural, and territorial realities. In other words, the population of a city is not only made by those living in it, but also of those travelling to it daily from other municipalities for consuming, leisure or as a working place.

The management experiences of urban/metropolitan spaces in Spain are not very different from those of other countries with a longer urban tradition. From the Social
Sciences, different contributions [5-7] have been made, which have helped to shape a series of malfunctions derived from the inadequateness of the publicly managed territorial areas to the functional realities and dynamics of this kind of spaces. Among the most important, the following ones can be underlined:

1. Political fragmentation implies a certain administrative complexity at the time of organizing the provision of public services. It can generate confusion and non-efficiency, lack of coordination and contradictory actions, which can derive in the appearance of institutional conflicts and disagreements, which diminish efficiency to the management of public resources.

2. There is a great difficulty in achieving common planning and managing fundamental policies for the dynamic city. The harsh reality of municipalities, as a cornerstone administrative organisation, leads to an individual planning of aspects, such as urbanism or fiscal actions. In the first case, even strong antagonisms between neighbouring municipalities can be found when designing and executing the planning, giving way to the appearance of urban imbalances and a disorganisation of the system of settlements. Without a common urban and fiscal policy in the municipalities of a supra-municipal area, it is very difficult to think of an effective cooperation and coordination. Other action lines present difficulties

Table 1. Demographic Evolution of the Main Agglomerations of Spain

\begin{tabular}{|c|c|c|c|c|c|c|c|c|}
\hline & 1900 & 1950 & 1960 & 1970 & 1981 & 1991 & 2001 & 2005 \\
\hline Madrid & 605.576 & 1.731 .917 & 2.331 .153 & 3.599 .953 & 4.466 .597 & 4.676 .036 & 5.021 .708 & 5.343 .726 \\
\hline Barcelona & 719.013 & 1.784 .292 & 2.337 .624 & 3.312 .089 & 3.894 .370 & 3.801 .248 & 3.797 .283 & 4.078 .998 \\
\hline Valencia & 376.077 & 799.046 & 882.122 & 1.187 .145 & 1.436 .780 & 1.513 .237 & 1.557 .407 & 1.655 .328 \\
\hline Sevilla & 214.251 & 529.065 & 641.278 & 792.377 & 991.337 & 1.035 .560 & 1.557 .407 & 1.655 .328 \\
\hline Málaga & 226.916 & 392.348 & 425.149 & 537.889 & 753.353 & 857.961 & 1.001 .480 & 1.100 .050 \\
\hline Bilbao & 201.932 & 447.600 & 637.702 & 901.307 & 1.039 .998 & 974.092 & 950.841 & 959.374 \\
\hline Ciudad Astur & 311.215 & 563.113 & 549.414 & 782.033 & 874.399 & 881.476 & 878.776 & 893.055 \\
\hline Zaragoza & 117.118 & 270.036 & 329.482 & 498.190 & 601.967 & 619.705 & 659.960 & 690.617 \\
\hline Alicante/Elche & 93.023 & 181.642 & 224.418 & 349.062 & 472.251 & 521.231 & 590.175 & 646.221 \\
\hline Cádiz-Jerez & 204.014 & 302.432 & 368.242 & 428.825 & 520.589 & 561.426 & 577.756 & 602.363 \\
\hline A Coruña-Ferrol & 172.379 & 319.926 & 381.636 & 413.188 & 483.344 & 503.495 & 523.088 & 541.903 \\
\hline Vigo & 114.789 & 284.034 & 305.353 & 378.096 & 476.055 & 498.909 & 520.714 & 540.923 \\
\hline Murcia & 131.912 & 260.023 & 297.806 & 304.522 & 371.237 & 432.851 & 495.666 & 535.222 \\
\hline Palma Gran Canaria & 62.862 & 203.034 & 251.938 & 330.819 & 448.434 & 444.598 & 475.278 & 505.516 \\
\hline Palma de Mallorca & 82.057 & 153.013 & 177.618 & 241.310 & 323.645 & 344.092 & 412.607 & 459.485 \\
\hline Granada & 125.567 & 246.725 & 250.923 & 293.699 & 366.612 & 402.130 & 442.373 & 455.339 \\
\hline San Sebastián & 74.551 & 187.443 & 237.104 & 336.984 & 387.135 & 373.820 & 383.043 & 392.799 \\
\hline Valladolid & 94.974 & 149.674 & 182.343 & 262.781 & 350.359 & 366.287 & 379.212 & 390.516 \\
\hline Santa Cruz Tenerife & 53.352 & 147.331 & 190.671 & 225.356 & 298.618 & 306.779 & 326.716 & 366.925 \\
\hline Almería & 65.028 & 101.537 & 118.419 & 162.827 & 210.446 & 247.495 & 312.687 & 341.487 \\
\hline
\end{tabular}


such as the case of the promotion strategies, and attempts to foster territorial development, which imply the adoption of wide consensus about the most suitable development model for the metropolitan space.

3. The areas organise themselves as a single unit, but in the area of political decisions taking, many of them adopt an individual point of view, even though the repercussions affect the whole population in these spaces. The agreements adopted in the central municipality affect the peripheral ones directly, and vice versa. This way, the citizens can be very directly affected by political decisions, about which they have no means of intervention or modification.

4. The territorial cooperation formulas, common in an important number of Spanish metropolitan areas (Fig. 1), have not caused, currently or in the recent past, an excessive advance in the management of metropolitan realities. Numerous causes, which have contributed to this situation, can be reported: assumption of indirect competences, indirect political direction and representation, specialisation in providing specific services, inadequacy of the territorial and economical planning instruments for the metropolitan territory.
The non-adjustment of the territorial, economic and functional dynamics of urban areas and the politicaladministrative reality in charge of such a management is vastly becoming more and more evident. The solution provided in Spain until the current democratic era has consisted of the absorption of the neighboring municipalities by the central one. In recent years, the trend has been to implement elements of territorial cooperation. The Spanish legal system makes the creation of new administrative organisations (communities, metropolitan areas or consortiums) possible, with the sole aim of providing a coordinated answer to the problems linked to the nonsuitability of the basic administrative limits to the ongoing processes. The efficiency of the cooperation organisations has not reached, however, the desired level of excellence, and has not been able to solve the malfunctions that they intended to correct.

The local urban and peri-urban units have not been characterised by excessive cooperation. Except in concrete and exceptional cases, the city councils in Spanish cities have planned their relationships with their neighbors more with an approach of conflict or mutual lack of confidence rather than with one of collaboration and coordination. Their distrust comes from both directions. The peri-urban units mistrust the capacity of the central municipality. The central

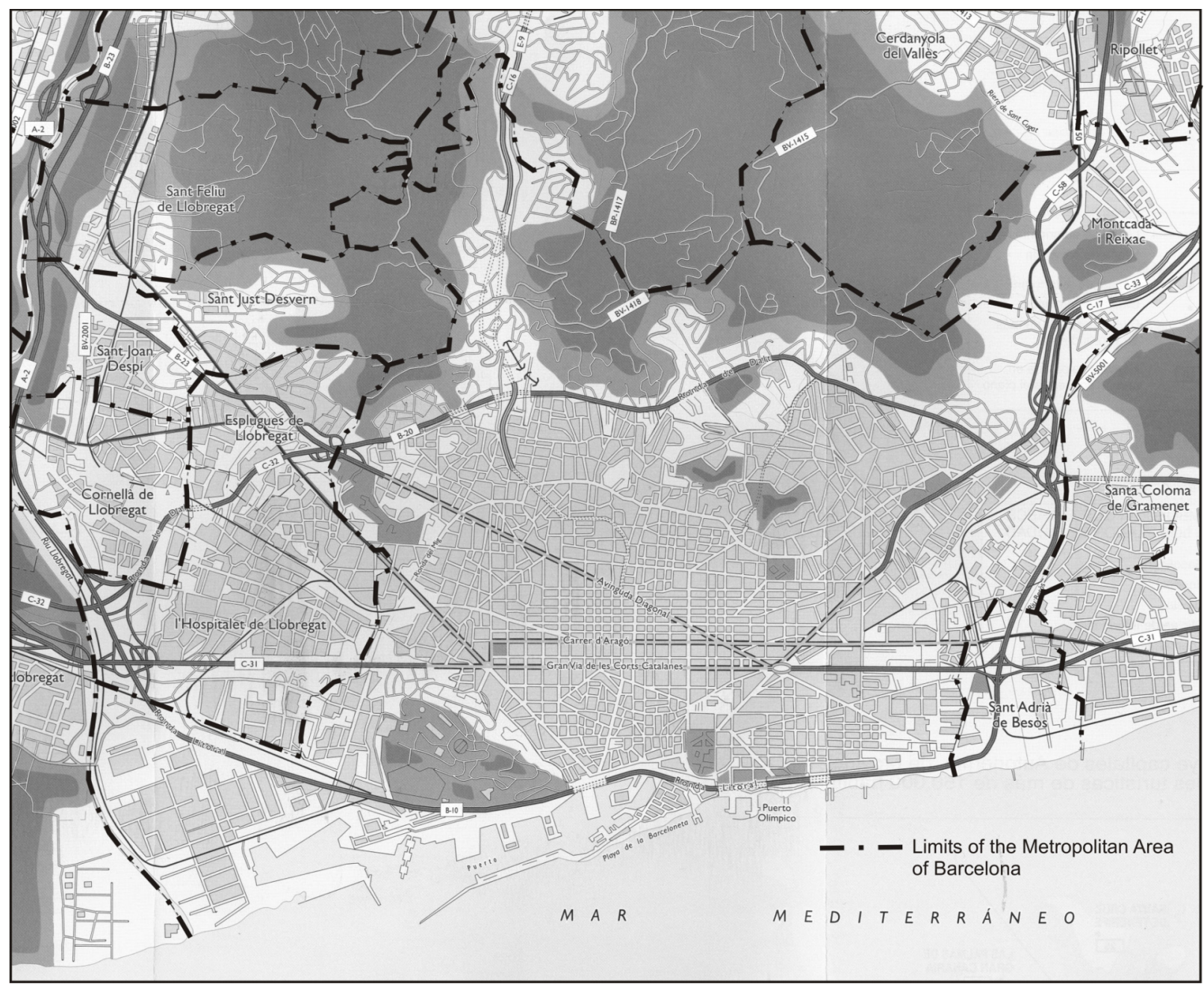

Fig. (1). Barcelona, an example of a physical city that has overwhelmed its municipal administrative limits. 
municipality mistrusts the opportunism of the surrounding units, which, due to their proximity, profit from the services, which are exclusively financed by the central municipality.

Apart from the situation of the metropolitan areas as being juridicial figures, the idea of finding new organising formulas for strongly urbanised spaces has been approached by different communities. One of the significant cases is the idea of creating the Ciudad Astur (Astur City), as an organisation that would include the urban triangle formed by Avilés-Gijón-Oviedo. This new concept coined by Fermín Rodríguez [8], has caused debate in Asturias. In other communities, this situation has been approached from the elaboration of territorial ordering documents of a subregional character, which, although not having been exclusively conceived for the establishment of planning norms at a metropolitan scale, do approach it in the corresponding cases. Such is the case of, amongst other Autonomies, the Basque Country or Andalucia, where referenced territorial ordering plans exist at a sub-regional level, city, and neighboring influenced area, where this space is understood as a functional whole. These planning instruments, which maintain the pre-existing political administrative network, are characterised by their youth, still being too premature to offer any type of reliable precedent.

These planning initiatives seek to manage a common space-functional unit in a coordinated way, aiming to avoid conflicts and the problems associated with the cornerstone political-administrative partitioning characteristic of the metropolitan spaces. These problems are, mainly, of two different types. The first ones, being of a more technical profile, are linked to the difficulty of formulating coordination instruments among the different administrative levels with responsibilities within these spaces (central, autonomy and local governments), in matters such as designing communication ways and ordering transport systems, designing and managing supply and health networks, fiscal issues or urbanism.

Meanwhile, the second set of problems is caused by political disagreements. Thus, in urban areas with a strong functional interrelation, there is a continuous risk of the unilateral decision of a municipality directly affecting the citizens of the neighboring municipalities, without these citizens having any kind of tool or mechanism of democratic control over such a decision, nor of having any part of its benefits. This is accompanied by a constant difficult relation between the central municipality (central city) and the peripheral ones, regarding the financing of those freely accessible services (green areas, parking lots, shorts and leisure facilities, etc.), which are financed by a municipality but consumed by the inhabitants of all of the urban area. Or over the urban uses and profiting of the territory, which is not difficult, as can be seen in many Spanish cities, which are contradictorily planned among the different spaces of the urban/metropolitan area.

\section{BRIEF BALANCE OF THE METROPOLITAN AREA AS A MANAGEMENT ENTITY}

The metropolitan areas are also juridical figures within the Spanish normative system. They are designed to give a reply to the existing dynamics in strongly urbanised areas, where, as afore mentioned, the territorial and socio- economical realities generate an urban continuum, which overwhelms the basic political-administrative limits.

In the 1970s, throughout the developmentism period, the Ministry of Housing elaborated a study to define those urban areas (central city and peripheral municipalities) with a potential of becoming metropolitan areas. Of the 30 initially estimated areas, only some of them, Madrid, Valencia, Zaragoza, and Barcelona, were formally constituted [9]. They were thought out as entities providing certain services (transport, waste management, water supply, etc.), and as a reference framework for the joint planning of policies.

Time has shown that in spite of the existence of a concern about the territorial ordering and organisation of these spaces, the option of these juridical formulas has proved to be non-satisfactory and inefficient [10]. Thus, for example, the Metropolitan Area of Barcelona, created in 1974, was cancelled in 1987 and substituted by three different entities, which have assumed its initial functions: the Transport Metropolitan Entity, the Metropolitan Entity of Hydraulic Services and Waste Treatment, and the Community of Municipalities of the Metropolitan Area of Barcelona. In the Valencia Community, the Metropolitan Area of L'Horta, created in 1946 and reformulated in 1995, was cancelled in 2001. Also the Bilbao one, created in 1945, was cancelled in 1980 .

When commenting on why the experience of these metropolitan areas has not been satisfactory, different researchers have based the failure on background politicaladministrative decisions. C. Levèfre [11] states that the institutional reinforcement of the autonomous communities smashed the metropolitan areas, as they were understood as a possible political counter power. This situation is not only evident in the case of Spain but also in the Portuguese, example, where at the beginning of 1990s the metropolitan areas of Porto and Lisbon were created [12].

In Spain, recent years have witnessed a strong delay in relation to new formulas of metropolitan government. Only partial initiatives or determined supra-local plans for managing specific services (transport, waterworks, etc.) have been promoted. Until now, the latest proposal aimed at implementing a metropolitan area, the one presented for the city of Vigo and its surrounding area, is also on its way to failure. Although, in this case before being implemented.

The city of Vigo and its metropolitan area is situated in the south of Galicia (Fig. 2), directly on the coast, and in the center of the so-called Galician-Portuguese Atlantic Axis, which is organised in linear form from Porto to the urban space of Coruña-Ferrol. Vigo is the most populated city in Galicia with almost 300,000 inhabitants, an average sized city according to the Spanish standards, but one that has permitted the development of a series of surrounding modest housing areas strongly linked to Vigo, and with the metropolitan space as a whole, which provide specialised functions within the territorial whole. This space has almost reached 500,000 inhabitants, being, clearly, the space with the largest population dynamism in the Autonomous Community of Galicia.

Vigo is the urban municipality par excellence, which holds the highest population agglomeration of Galicia, extending from Redondela to the North, to Nigrán to the 


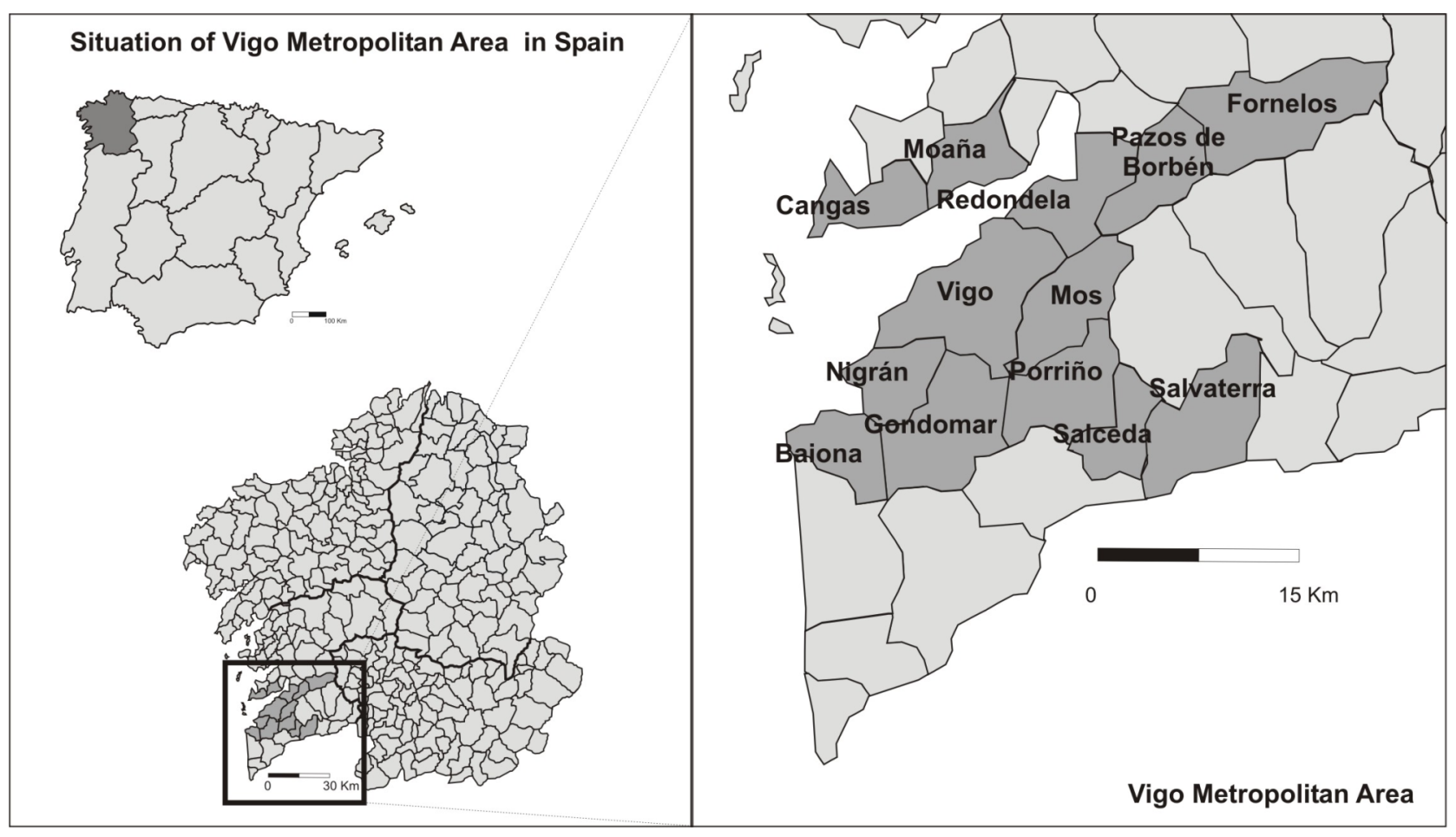

Fig. (2). Situation of Vigo metropolitan area in Spain.

south in a scattered urban continuum (with the exception of the central space of Vigo). As we move outwards from the urban centre, we find a group of municipalities, which in other times could have purely rural characteristics, but which are nowadays being considered small urban nucleus and spaces of transition towards territories, which already have a marked rural character, such as Fornelos de Montes, Pazos de Borbén, Salceda de Caselas, and Salvaterra de Miño. This urban-rural gradient is materialised in the levels of physical and human occupation of the territory, which decreases as we distance ourselves from the central point. We are also before the most industrialised and dynamic space at a business level in Galicia, with a productive basis founded on the automobile industry, and in the use of endogenous products, in particular, those derived from fishing. Due to its situation, Vigo can be considered, in fact, the functional capital of the Galicia-North of Portugal Euroregion, as it is placed half way between the principal Galician cities and the north of Portugal.

La election of the Metropolitan Area as an administrative entity has as its precedents the creation of the Mancomunidade (Municipalities Community) of Vigo, created in 1993, with the aim of jointly planning and managing a series of service that affect all of them. Its dynamics and progressive setting favor the appearance of a cooperative culture between the local entities, which led the mayors of the Mancomunidade to approve the Declaración de Soutomaior (Soutomaior Declaration) in 1999. In this declaration, the beginning of a process of creation of a Metropolitan Area is formally agreed, as the local leaders are convinced about pertaining to a functionally integrated space, with multiple interrelations and common problems and, also, the necessity to obtain a better efficiency, through cooperation, when providing services.
From this moment on, the development of new metropolitan institution was implemented was thought out as a administrative entity that would assume the effective transfer of those member municipalities, Province Deputation and Autonomous Government competences, and resources, which were estimated to be managed in a better way by this organisation (transport, economical promotion, water, waste and, even, urban ordering management). The Metropolitan Area would implicate the creation of particular government bodies, the Metropolitan Council, and of guaranteed financing sources, proceeding from transfers by the member municipalities, state funds, and those obtained through tax collection and public pricing from provided services. Its administrative character was reinforced with sanctioning powers in matters of its competence, expropriating, etc.

This project was unilaterally modified by the Autonomy Government by means of a presentation, made in March 2006, of a document creating a Metropolitan Consortium, substituting the previous Area. Although both are contemplated figures within the local Spanish local legislations, the differences are considerable. The proposal of a Consortium presents a fundamental change, as it slows down the transfer of political-administrative competences from the Regional Government, thus, becoming just an organism of managing delegated competences, without guaranteeing funding mechanisms. At the same time, the planned government bodies become merely symbolic, as the idea is to make the Consortium presidency rotate every six months, and that even in some aspects, such as transport; the presidency falls to the Autonomy Government.

The reaction of the local institutions and of its political representatives, belonging to the three main political forces of Galicia, has practically been unanimous in rejecting the 
new scenario planned by the Autonomy institution. Declarations were made that insist on the non-confidence of the major parties from the Xunta de Galicia regarding the affected municipalities rejecting the proposals put forward by the Autonomy Government regarding the creation of the Metropolitan Area. At the end of the day, this is a new case of autonomic neo-centralism, reinforcing the thesis of $\mathrm{C}$. Lefèvre [7], when regarding the Spanish case that creating the autonomies has slowed down the development of the metropolitan areas. The root problem appears to be the fear of the appearance of a political counter power.

The main issue is not just the planning of the metropolitan areas, organisations which are very often rejected due to their weak operational form, and that have experienced a path of failure and excessive administrative profile. (On the contrary the fundamental question is to identify the key aspects that in the Spanish case cause difficulties for their creation and which have taken them to a situation of an intermediate solution with limited achievement. As experts, such as C. Lefèvre [11] or P. Cantor [13], have commented about Spain in recent declarations (newspaper Faro de Vigo, $31^{\text {st }}$ March), the key is found in the autonomic neo-centralism, and in the fear of losing territorial leadership, shown by the autonomic governments when affronted by the cities and their metropolitan spaces. Resistance to change is at least in part founded in the protective instincts of the existing authorities.

\section{REFERENCES}

[1] Leboreiro A. De la teoría a la práctica en la planificación territorial. Rev Urban 1999; 3: 68-80.

[2] Vegara A, De Las Rivas JL. Territorios inteligentes. Madrid: Fundación Metrópoli 2004.

[3] Perritaz S. Intenercommunalites, agglomesration et fusion de comunes: l'optimal et le posible dans les zones urbaines suisses. Friburgo: Universidad de Friburgo 2003.

[4] Serrano Martinez JM. Aglomeraciones y áreas urbanas en España, dimensiones y tendencias. Breves Precisiones [Lurralde, 2006; 9: 115-42]. Available from: http://www.ingeba.euskalnet.net/lurralde/ lurranet/lur29/29serra/29serra.htm

[5] Daffon B. Analyse socio-économique de tente-deux fusions de communes dans le canton de Fribourg. Universidad de Friburgo 2003.

[6] Simmons M. El caso de Londres. Gobierno y gestión del planeamiento. Rev Urban 2001; 5: 40-9.

[7] Talia M. La pianificazione del territorio. Milán: Il sole 24 Ore 2003.

[8] Rodriguez GF, Menendez FR. Ciudad y región en Asturias. Ciudad Astur, un espacio-proyecto de Desarrollo Regional. Oviedo: Cecodet 2004

[9] Galofres I, Crespi J. Las grandes ciudades. In: Informe del Gobierno Local. Madrid: MAP 1992.

[10] Font I, Lovet T. La renovación del poder local: avances en la configuración jurídica e institucional del gobierno local. Anuari del Govern Local. Barcelona: Fundación Democracia y Gobierno Local 2001; pp. 13-37.

[11] Lefevre C. La planificación de las metrópolis europeas. Rev Urban 2003; 8: 78-92.

[12] Rio Fernandes JA. A cidade, os municipios e as políticas: O caso do Grande Porto. Rev Sociol 2003; 13: 227-51.

[13] Savitch HV, Cantor P. Cities in the Internacional Marketplace: the political economy of urbam developement in North America and Western Europe. Princeton University Press 2002. 